\title{
PEMODELAN BERBASIS AGEN (ABM) UNTUK PENGELOLAAN AKTIVITAS MIGRASI MUSIMAN NELAYAN ANDON CUMI-CUMI DI PULAU SALURA
}

\section{Agent Base Model For Seasonal Migration Activity of Squid Andon Fishers at Salura Island}

\author{
'D. Susiloningtyas ${ }^{1}$, M. Boer ${ }^{2}$, L. Adrianto² dan F. Yulianda ${ }^{2}$ \\ 'Departemen Geografi FMIPA Universitas Indonesia, Kampus Baru UI Depok, Indonesia \\ ${ }^{2}$ Program Pengelolaan Sumberdaya Pesisir dan Lautan, Institut Pertanian Bogor \\ "email: dewi.susiloningtyas@gmail.com \\ Diterima 14 April 2015 - Disetujui 6 Juni 2015
}

\begin{abstract}
ABSTRAK
Perikanan cumi-cumi di Pulau Salura dibentuk oleh adanya agen nelayan andon, penduduk lokal, serta sumberdaya cumi-cumi. Kehadiran nelayan andon yang melakukan migrasi musiman dari Tanjung Luar di Pulau Lombok sampai ke Pulau Salura dengan aktivitas penangkapan cumi-cumi menjadikan sistem perikanan cumi-cumi ini menjadi berbeda dengan daerah lain. Intensitas migrasi dari nelayan andon yang tinggi berpengaruh terhadap perilaku penduduk lokal, serta kelimpahan sumberdaya cumi-cumi yang ada. Tujuan dari penelitian ini adalah mengkaji model pengelolaan aktivitas migrasi musiman dengan pengaturan alat tangkap yang dibawa. Metode yang digunakan adalah dengan pemodelan berbasis agen (ABM/Agent Base Model) melalui perangkat lunak Netlogo 6.2. Hasil penelitian menunjukkan bahwa pengaturan jumlah unit kapal yang terlibat dalam penangkapan cumi-cumi dalam waktu satu tahun harus diatur. Terdapat sembilan periode migrasi musiman yang dilakukan,sehingga model pengaturan jumlah unit kapal yang optimal untuk dapat menjaga kelimpahan cumi-cumi dan jumlah panenan nelayan adalah sebanyak 18 unit kapal setiap tahunnya. Populasi kelimpahan cumi-cumi yang dihasilkan sebesar 330 kuintal dengan masa regenerasi 42 hari, dan menghasilkan jumlah panenan sebesar 913 kuintal.
\end{abstract}

Kata Kunci: Pulau Salura, migrasi musiman, ABM, cumi-cumi, nelayan andon

\begin{abstract}
Squid fishery system at Salura Island maked by multiple agent, as andon fishers, local peoples and squid resources. The presence of andon fishers who seasonally migrate from Tanjung Luar of Lombok Island to Salura Island with squid fishing activities makes the squid fishery system is to be different from other regions. The intensity of the migration of high andon fishers affected the behavior of the local population, as well as squid abundance of resources available. The purpose of this study was to manage the number of ships or fishing gear. The method is agent-based modeling (ABM / Agent Base Model) by used Netlogo 6.2 software. The results showed that the behavior of the agent can be analyzed from behaviors and activities. Setting the number of ships involved in catching squid in a year should be set. There are nine periods of seasonal migration is done, so that the optimal number of ships to be able to maintain the abundance of squid and the number of fishers are harvesting as many as 18 ships annually. The abundance of squid produced by 330 quintal with 42-day period of regeneration, and the squid harvest is 913 quintal.
\end{abstract}

Keywords: Salura Island, seasonal migration, $A B M$, squid, andon fishers 


\section{PENDAHULUAN}

\section{Latar Belakang}

Pulau Salura yang terletak di Kabupaten Sumba Timur Propinsi Nusa Tenggara Timur, merupakan daya tarik bagi nelayan andon cumi-cumi yang berasal dari Tanjung Luar Pulau Lombok di Provinsi Nusa Tenggara Barat,untuk melakukan migrasi musiman secara periodik dengan kegiatan pemanfaatan sumberdaya cumi-cumi. Kegiatan migrasi musiman untuk melakukan aktivitas penangkapan selalu dimotivasi oleh adanya hasil tangkapan yang lebih baik, serta adanya masalah over exploitation di daerah asal (Nunan, 2006). Menurut Cassel et al. (2005), pembahasan tentang migrasi selalu terkait dengan lingkungan. Hubungan antara keduanya dapat diidentifikasi dari bagaimana sumberdaya dapat diekstrak atau dimanfaatkan menurut tingkat dan efektifitasnya oleh penduduk migran. Berdasarkan konsep Overa (2001), migrasi yang terkait dengan perikanan merujuk kepada konsep migrasi musiman dan sirkuler. Dalam penelitian ini migrasi yang dilakukan oleh nelayan andon cumi-cumi adalah migrasi musiman, karena lebih terkait dengan konsep sumberdaya, daripada aspek ekonomi dan politik. Migrasi musiman ke Pulau Salura ini sangat dipengaruhi oleh variasi musim yang ada. Sebagai sebuah sistem ekologi, pola perkembangan dan dinamika Salura dapat ditentukan oleh komponen-komponen dalam sistem perikanan cumi-cumi yang saling berinteraksi secara dinamis.

Sebagai implikasi dari perkembangan interaksi yang terjadi diantara komponenkomponen tersebut dalam kaitannya dengan kegiatan penangkapan cumi-cumi, makasemakin berkembangnya Pulau Salura menjadi daerah tujuan migrasi, maka akan semakin tinggi intensitas kegiatan yang ada. Terjadinya kerusakan dan ketidakseimbangan ekosistem pasti akan terjadi, seperti misalnya ketidakseimbangan ekosistem pantai oleh banyaknya tenda tempat tinggal dan alat tangkap di sepanjang pesisir pantai, berkurangnya kesuburan perairan untuk habitat cumi-cumi.

Untuk dapat melakukan pengelolaan sistem perikanan cumi-cumi dan interaksinya dengan nelayan andon yang datang, maka dilakukan Pemodelan berbasis agent (ABM/ Agent Base Model). ABM adalah pendekatan pemodelan dalam menganalisis sistem yang kompleks dalam dunia nyata. Menurut Health \& Hill (2010) terdapat tiga hal yang mengawali pemunculan metode untuk pemodelan ini, yaitu (1) kemunculan dan perkembangan komputer, (2) kesadaran akan kebutuhan untuk kompleksitas, serta (3) pemahaman akan sistem. Saat ini pemodelan berbasis agen menjadi metode pemodelan yang tepat untuk alternatif pemecahan masalah dalam sistem yang kompleks. Pada pemodelan berbasis agen, sistem terbangun atas interaksi agen-agen pada sebuah lingkungan tertentu (Macal \& North, 2010).

Hubungan antara masalah penelitian dan tools yang digunakan adalah pada kemampuan software Netlogo yang dapat memberikan solusi keputusan dalam kompleksitas masalah perilaku nelayan andon dalam penangkapan cumi-cumi dengan populasi cumi-cumi yang seharusnya dapat terjaga. Netlogo adalah salah satu tools yang dapat digunakan dalam melakukan simulasi dengan pemodelan berbasis agen. Program Netlogo ini dapat mendeteksi bagaimana agen nelayan andon yang digambarkan dalam kepemilikan jumlah kapal dalam perilaku penangkapan yang paling optimal, sehingga signifikan atau selaras dengan jumlah populasi cumi-cumi yang ada.

Schluter et al. (2009) menggunakan ABM untuk mengidentifikasi aspek ekologi dan ekonomi keberlanjutan ekosistem di delta sungai Amurdaya di Asia Tengah. Penelitian dengan pemodelan ABM juga dilakukan oleh Gao \& Atakelty (2011), yaitu pemodelan untuk melakukan pengaturan kegiatan wisata memancing dengan konservasi lingkungan terumbu karang. Prototype ABM untuk pengelolaan perikanan di wilayah pesisir dikembangkan oleh Yu Run et al. (2009), yang menyatakan bahwa pendekatan ABM adalah pemodelan yang efektif untuk dapat menggambarkan pola dan perilaku spasial temporal, serta interaksi dari setiap agen yang terlibat dalam suatu sistem.

\section{Perumusan Masalah}

Pada diagram kerangka permasalahan terlihat bagaimana bentuk konektivitas nelayan migran cumi dan kelimpahan cumi-cumi di pesisir dan lautan Pulau Salura. Perencanaan dan pengambilan kebijakan untuk pengaturan sistem perikanan cumi yang terjadi di pulau ini harus mempertimbangkan berbagai hal seperti kondisi saat ini, proyeksi masa depan serta tujuan pengadaan atau pengaturan untuk masa depan. 


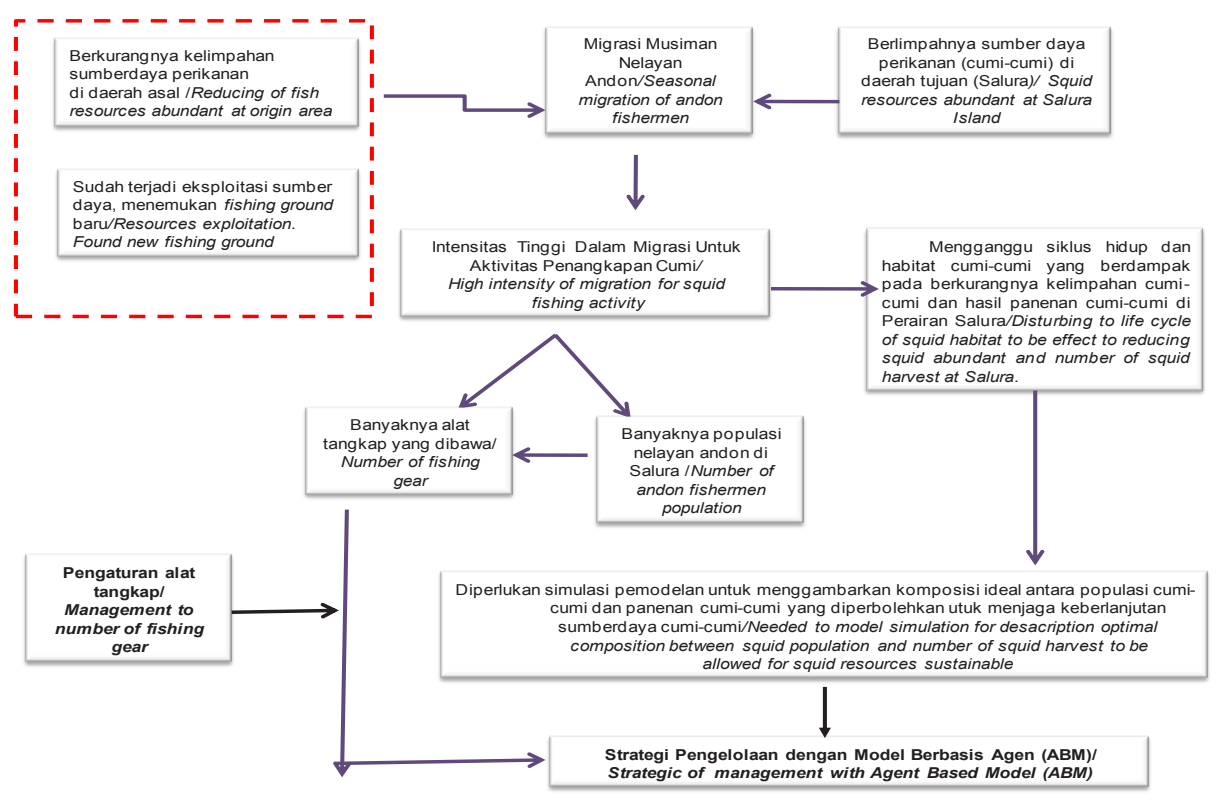

Gambar 1. Diagram Perumusan Masalah

Figure 1. Formulation Reseach Diagram

Sumber : Analisis Data, 2012/Source: Data Analysis, 2012

Kondisi yang tertantang dalam sistem ini adalah pada komponen utama yaitu keberadaan sumberdaya cumi-cumi dan alat tangkap yang digunakan, populasi nelayan andon, serta penduduk lokal yang terus bertambah. Hal ini menyebabkan terjadinya kompleksitas dari sistem perikanan cumi-cumi di Pulau Salura.

\section{Tujuan Penelitian}

Tujuan peneltian ini adalah melakukan simulasi pemodelan untuk mengatur jumlah alat tangkap, yaitu kapal payang cumi yang dapat dibawa untuk melakukan aktivitas penangkapan di Pulau Salura. Pengaturan alat tangkap ini perlu dilakukan karena sesuai dengan wacana regulasi dari pemerintah lokal untuk mengurangi beban Pulau Salura sebagai tempat tujuan migrasi dan dapat mengurang populasi nelayan andon yang terus bertambah, serta menjaga keberlanjutan populasi cumi-cumi di perairan Pulau Salura. Asumsi dari pengurangan atau pembatasan alat tangkap ini adalah karena semakin banyak alat tangkap yang dibawa oleh nelayan andon, maka intensitas migrasi akan menjadi lebih tinggi juga, sebaliknya jika ada pembatasan alat tangkap yang dibawa oleh nelayan andon, maka aktivitas penangkapan cumi-cumi juga akan berkurang, yang tentu saja berdampak positif terhadap regenerasi cumi-cumi untuk meneruskan siklus hidup secara alami dan menjaga kelimpahan cumi-cumi.
Kompleksitas sistem perikanan cumi-cumi di Pulau Salura tergantung kepada dua komponen utama, yaitu alat tangkap atau jumlah kapal yang terlibat dan populasi cumi-cumi. Alat tangkap menjadi komponen yang masih fleksibel untuk diubah dan dikendalikan, berbeda halnya dengan komponen yang lain, yaitu cumi-cumi. Keterbatasan perubahan keberlimpahan cumi-cumi menjadi komponen yang rentan dan mempengaruhi kebijakan sistem perikanan cumi-cumi yang ada. Dalam mengakomodasi keperluan ini, maka tujuan penelitian ini adalah melakukan analisis pemodelan yang mampu memproyeksikan kemampuan cumi-cumi terhadap tantangan tersebut, dengan tetap menempatkan nelayan cumi sebagai fokus utama. Analisis ini menghasilkan sebuah model yang menyediakan rekomendasi desain pemanfaatan yang akomodatif bagi sistem perikanan cumi-cumi. Kerangka penelitian dan kerangka kerja dari pemodelan berbasis agen dalam penelitian ini disajikan dalam Gambar 2.

\section{METODOLOGI}

\section{Lokasi dan Waktu}

Lokasi penelitian adalah di Pulau Salura Sumba Timur sebagai daerah tujuan migrasi. Pulau Salura merupakan satu dari pulau kecil terluar yang terletak di sebelah tenggara Pulau Sumba. Secara administrasi Pulau ini masuk di Kecamatan Karera Kabupaten Sumba Timur. Pulau ini terletak satu 
gugus dengan Pulau Kotak dan Pulau Mengkudu di bagian barat (Gambar 2). Pulau yang dikelilingi Samudera Hindia ini memiliki topografi pantai landai di bagian utara dan curam di bagian selatan. Sebagian besar bentuk lahan adalah perbukitan batuan dan hanya sekitar $25 \%$ lahan dataran yang dihuni masyarakat Desa Salura. Pulau Salura dihuni oleh 568 penduduk dengan jumlah rumah tangga sebanyak $138 \mathrm{KK}$. Kepadatan penduduk berkisar 52 orang tiap $\mathrm{km}$ persegi, dengan luas wilayah $29 \mathrm{~km}^{2}$.

Waktu penelitian dilakukan berdasarkan musim penangkapan oleh nelayan, yaitu antara bulan Juli sampai dengan Desember 2012. Jenis data yang dikumpulkan adalah data primer dansekunder. Data primer diperoleh dengan metode penelitian survei. Alat yang digunakan untuk pengumpulan data primer adalah dengan menggunakan kuesioner. Kuesioner dirancang dengan tepat supaya variabel dan data dari sumbernya dapat diperoleh dan diidentifikasi secara tepat. Adapun data sekunder diperoleh dari instansi yang terkait serta data dari beberapa publikasi terdahulu.

\section{Metode Pengumpulan Data}

Pengumpulan data dilakukan dengan metode penelitian survei, dengan pengumpulan data primer sebagai data utama. Alat yang digunakan adalah kuesioner yang disusun secara detail dan rinci untuk dapat menghasilkan data primer yang mempunyai kesahihan dan validitas tinggi. Pengumpulan data sekunder dikumpulkan melalui data publikasi dari instansi terkait.
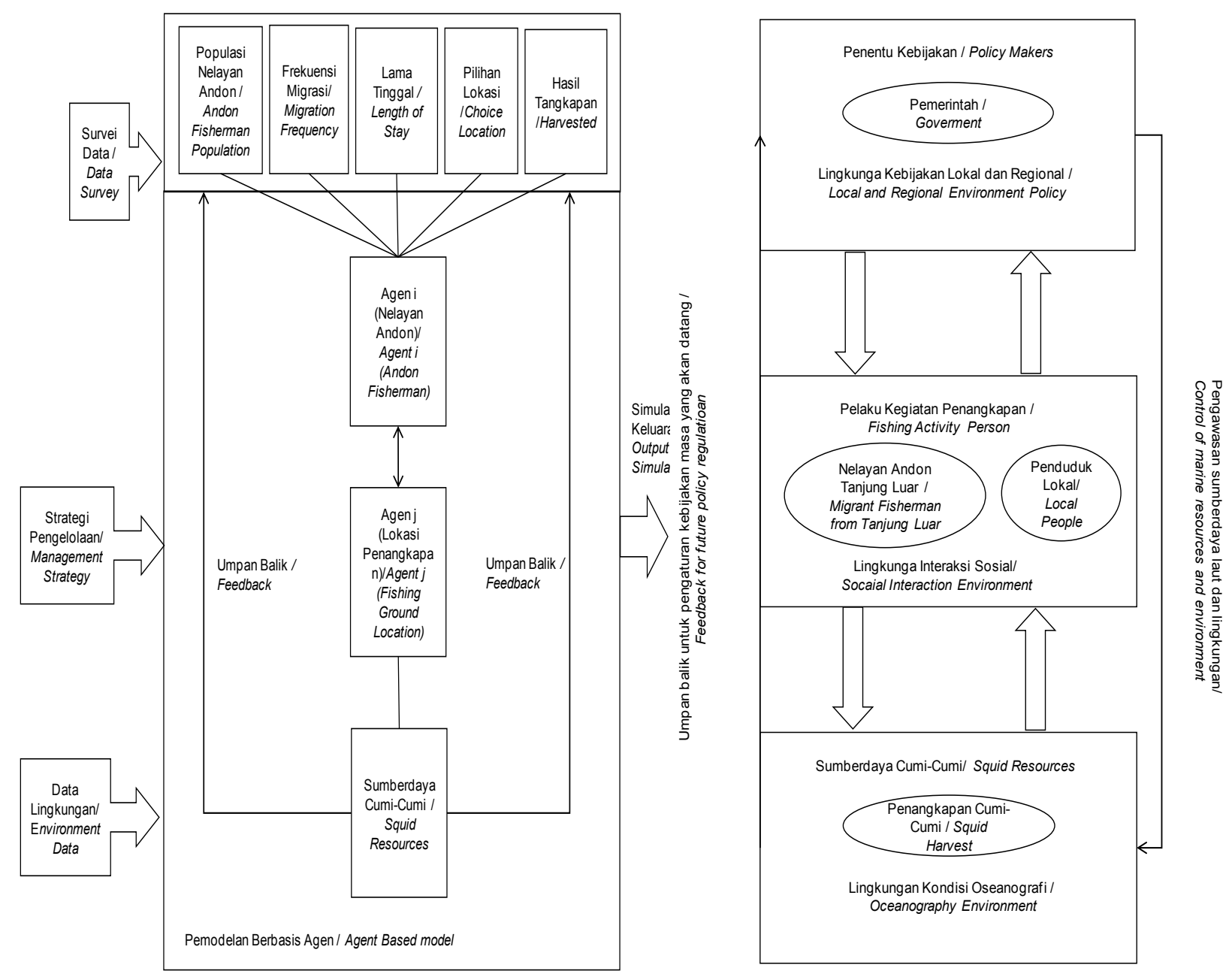

\section{Gambar 2. Kerangka Pengelolaan Berbasis Agen dalam Perikanan Cumi-Cumi} Figure 2. Framework of Agent Base Management in Squid Fishery

Sumber : Gao \& Atakelty (2011) dengan modifikasi/Source :Modification Gao \& Atakelty (2011) 


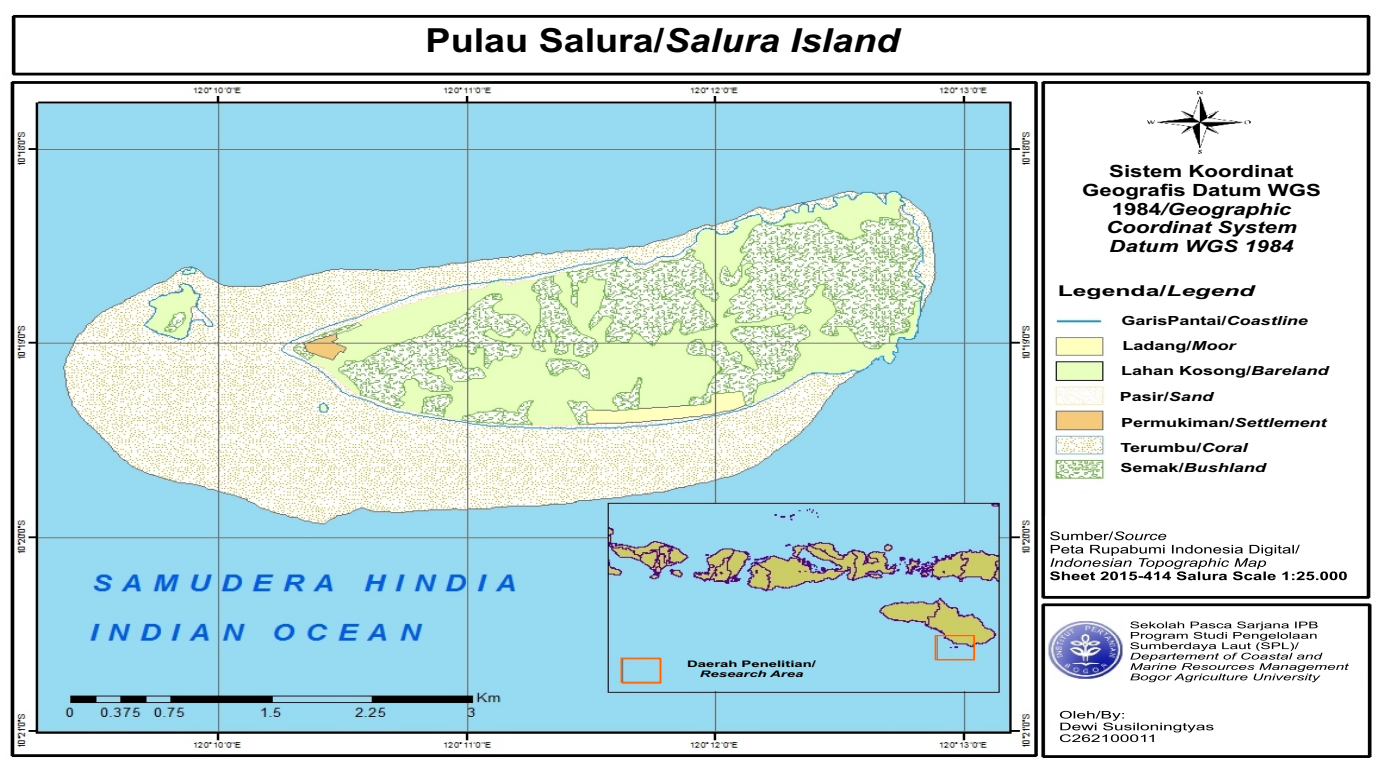

Gambar 3. Lokasi Daerah penelitian

Figure 3. Research Area

Sumber : Peta Rupabumi Indonesia Digital,Lembar 2015-414 Salura/ Source : Digital Map of Indonesia Topography, sheet of 2015-414 Salura

Data yang dikumpulkan adalah data tentang agen (cumi-cumi, nelayan andon, penduduk lokal, pemerintah, serta sektor swasta), relasi antar agen (proses interaksi), serta lingkungan tempat agen ini bergerak dari data oceanografi (lingkungan pesisir dan lautan Pulau Salura). Data tentang populasi cumi-cumi yang diasumsikan sebagai jumlah kelimpahan cumi-cumi, tidak dilakukan secara insitu, tapi merupakan data primer dari hasil tangkapan yang diperoleh nelayan. Untuk memodelkan permasalahan dalam sistem ini digunakan Netlogo 6.2 sebagai salah satu tools untuk pemodelan berbasis agen.

\section{Metode Analisis Data}

Analisis yang dilakukan merupakan tahapan dalam membangun model, yaitu mulai dari (1) menentukan tujuan pembuatan model yang merupakan hasil akhir dari pembuatan model yang akan digunakan dan dianalisis; (2) menentukan pengaturan model-model alternatif berdasarkan variabel dan perubahan yang ada; (3) penggambaran model yang sudah selesai dijadikan sebagai dasar untuk pembuatan dan pengembangan model awal; (4) melakukan validasi dan verifikasi model; (5) pembuatan model alternatif dengan beberapa skenario yang dibuat sebagai bentuk intervensi terhadap model yang akan diuji.

Analisis terfokus pada tiga elemen utama, yaitu melakukan analisis deskriptif kuantitatif dari perilaku agen nelayan andon beserta karakteristik jumlah alat tangkap yang dimiliki, produktivitas kapal yang dimiliki, serta hasil tangkap per tahun, serta analisis pola migrasi yang dilakukan. Untuk agen dari sumberdaya cumi-cumi, analisis yang dilakukan adalah mendeskripsi siklus hidup cumi-cumi serta waktu regenerasi cumi-cumi yang terjadi. Dengan analisis ini dapat dilakukan pendugaan terhadap waktu yang diperlukan cumi-cumi untuk dapat munculnya kehidupan dari individu yang baru.

\section{HASIL DAN PEMBAHASAN}

\section{Pembentukan Parameter Analisis}

Pembentukan parameter analisis dibuat berdasarkan tujuan yang akan dicapai. Adapun tujuan dari pembuatan model penangkapan oleh nelayan andon ini adalah agar diperoleh suatu model atau gambaran yang ideal dari keberlanjutan sumberdaya cumi-cumi berdasarkan jumlah panenan cumi-cumi yang diperbolehkan untuk masa depan sesuai dengan kondisi dan skenario yang dibuat, sehingga dapat terintegrasi dengan kondisi lingkungannya, yaitu mempertahankan keberlanjutan mata pencaharian tapi sekaligus juga memberi waktu regenerasi cumi-cumi untuk tumbuh. Fokus pemodelan ini adalah pada pergerakan nelayan andon yang dicerminkan dari jumlah kapal yang bergerak dari Tanjung Luar ke Salura, serta dari Salura ke lokasi fishing ground berdasarkan waktu penangkapannya. 
Aspek penting parameter analisis yang digunakan adalah (1) parameter kualitatif dan (2) parameter kuantitatif. Parameter kualitatif yang dianalisis adalah munculnya kondisi bahwa ada produktivitas kapal yang harus diperhatikan dalam aktivitas penangkapan, sehingga harus kembali ke base camp setelah kapal penuh, munculnya kondisi bahwa harus ada kapal yang kembali ke Tanjung Luar yang hilir mudik dalam waktu 3 hari 2 malam untuk setiap kali perjalanan menjual hasil tangkapan ke TPI Tanjung Luar. Parameter kuantitatif dianalisa dari banyaknya kapal yang melakukan penangkapan, waktu regenerasi cumi-cumi, serta hasil tangkapan atau panenan cumi-cumi.

Pada parameter kualitatif, batasan maksimal yang dapat diterima adalah bahwa ada perbedaan produktivitas kapal yaitu kondisi produktivitas kapal besar dan kecil. Hal ini yang membedakan jumlah tangkapan dan juga waktu beroperasi kapal dalam satu kali trip penangkapan. Adapun pada parameter kuantitatif menunjukkan bahwa ada batasan tentang keterlibatan jumlah kapal dalam hal ini alat tangkap yang dibawa dalam periode waktu satu tahun, serta waktu regenerasi cumi-cumi, dimana kedua parameter ini nantinya akan mempengaruhi kondisi populasi cumi-cumi dan hasil pemanenan cumi nya. Aktivitas penangkapan juga dipengaruhi oleh waktu migrasinya. Pada bulan Desember,
Januari dan Februari, nelayan andon tidak melakukan aktivitas penangkapan, sehingga berpengaruh terhadap regenerasi cumi-cumi dan populasi cumi-cumi.

\section{Verifikasi dan Validasi Model}

Tujuan dari proses verifikasi dan validasi model adalah memastikan bahwa model sudah mempresentasikan kondisi yang sebenarnya. Proses verifikasi model dilakukan dengan melakukan kajian terhadap pergerakan atau aktivitas agen dalam model. Adapun aktivitas nelayan digambarkan melalui kepemilikan alat tangkap atau jumlah unit kapal dari setiap agen. Tahapan verifikasi berikutnya adalah melakukan pemeriksaan terhadap kesesuaian pergerakan agen berdasarkan pola migrasi musiman dan rute serta waktu dari base camp ke lokasi fishing groundnya. Proses validasi diperlukan terutama untuk menguji kesesuaian model terhadap kondisi sebenarnya. Validasi dilakukan terhadap aspek perilaku agen dan interaksinya, lama waktu pergerakan serta banyaknya atau jumlah agen yang melakukan interaksi. Jika muncul interaksi dari agen dan perilakunya terhadap lingkungan dimana agen berada, maka validasi model sudah dinyatakan benar dan sesuai dengan kinerja modelnya. Dalam penelitian ini pergerakan nelayan andon dan interaksi terhadap lingkungan perairan

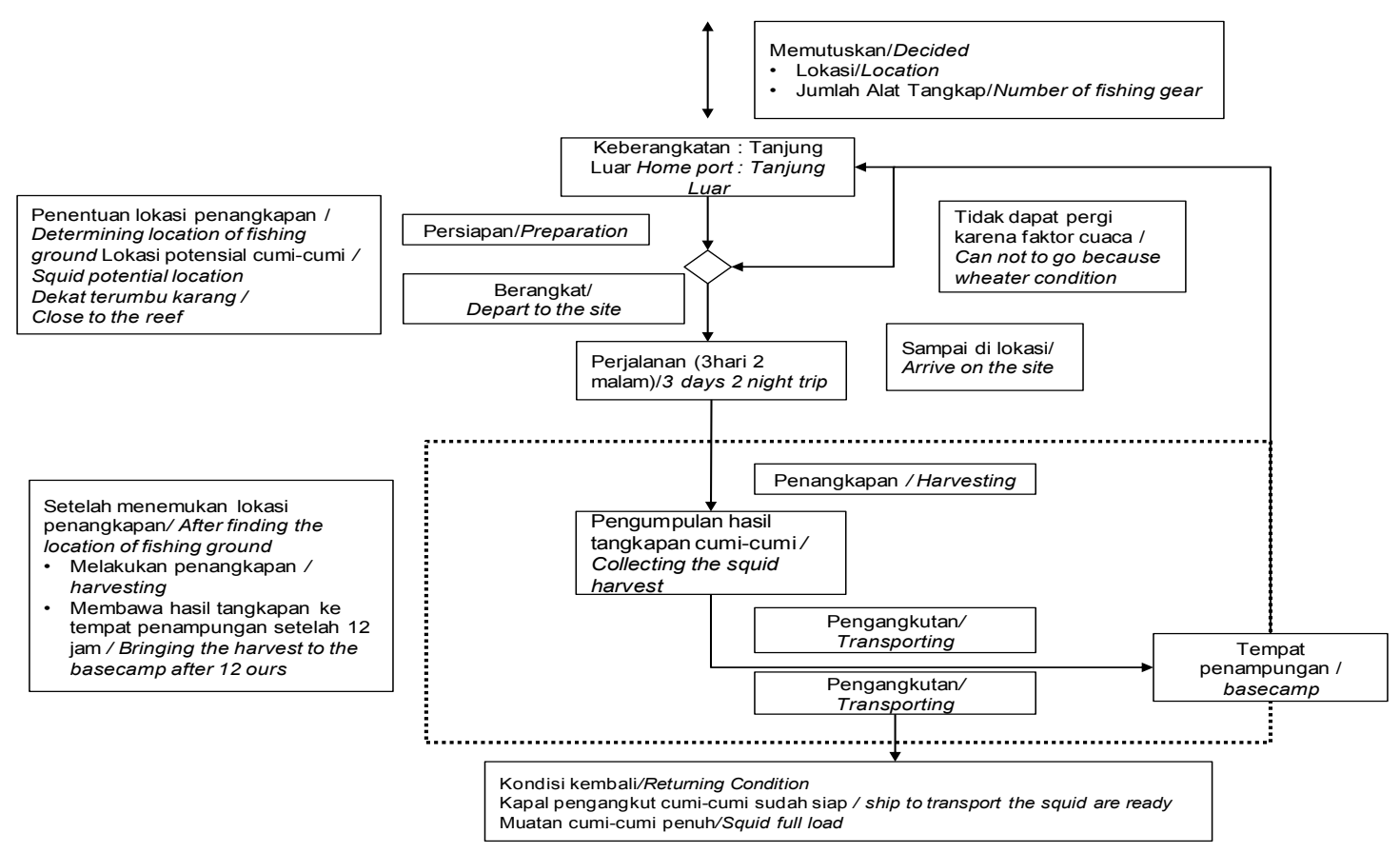

Gambar 4. Keputusan Aktivitas Penangkapan Cumi-Cumi Figure 4. Decision Making of Squid Fishery Activity

Sumber : Yu Run et al. (2009) dengan modifikasi/Source : Modified Yu Run et al. (2009) 
dan pesisir Salura, serta sumberdaya yang ada telah terverifikasi dan tervalidasi, sehingga model ini layak digunakan dalm analisis.

\section{Pola Migrasi Musiman Nelayan Andon}

Pola migrasi berdasarkan waktu migrasi dideskripsi dari frekuensi melakukan migrasi dan lama tinggal di Pulau Salura sebagai daerah tujuan migrasi. Frekuensi migrasi adalah periode waktu melakukan migrasi musiman dalam kurun waktu satu tahun. Frekuensi migrasi dapat mengindikasikan bagaimana nelayan cumi migrant melakukan mobilitas musiman berdasarkan waktu terkait musim dan kondisi sumberdaya cumi-cumi di perairan Salura. Dari hasil penelitian tampak bahwa frekuensi melakukan migrasi dapat dibedakan berdasarkan kategori waktu frekuensi tinggi, sedang dan rendah. Frekuensi tinggi itu adalah periode melakukan migrasi musiman dalam waktu satu tahun sebanyak lebih dari sembilan kali dalam satu tahun. Nelayan yang melakukan migrant dengan kategori frekuensi tinggi jumlahnya hanya sebesar 5,7 persen. Nelayan dengan frekuensi migrasi rendah, yaitu melakukan migrasi sebanyak kurang dari tujuh kali dalam setahun sebesar 5,7 persen juga, sehingga frekuensi melakukan migrasi didominasi oleh frekuensi sedang yaitu tujuh sampai sembilan kali dalam waktu setahun. Nelayan dengan pola migrasi frekuensi tinggi adalah sebesar 88,6 persen. Pola migrasi berdasarkan waktu frekuensi migrasi dapat dilihat pada gambar 5. Pola migrasi berdasarkan intensitas waktu yang digunakan juga dapat dideskripsi dari lama tinggal di daerah tujuan migrasi (seperti ditunjukkan pada Gambar 5), yaitu Pulau Salura. Hasil penelitian menyebutkan bahwa lama tinggal nelayan cumi di daerah tujuan migrasi sebagian besar adalah antara enam sampai sepuluh hari, yaitu sebesar 65,7 persen. Sementara nelayan migran dengan lama tinggal enam sampai sepuluh hari adalah sebesar 22,9 persen, sedangkan nelayan dengan lama tinggal kurang dari lima hari adalah sebesar 11,4 persen.

Lama dan singkatnya lama tinggal di daerah tujuan migrasi sangat mempengaruhi hasil tangkap di kedua periode musim. Hal ini dapat dijelaskan dengan melakukan korelasi antara hasil tangkap di dua musim yang berbeda dengan variasi musim, yaitu pada saat musim barat dan musim timur. Kegiatan migrasi musiman yang dilakukan oleh nelayan andon ini mempunyai pola yang sangat teratur. Hal ini disebabkan karena aktivitas penangkapan yang dilakukan selalu menyesuaikan periode musim dan kelimpahan cumi-cumi di daerah fishing ground cumi di sekitar perairan Salura.

Pola migrasi musiman ini dapat dibedakan menjadi tiga periode kegiatan berdasarkan musim timur, musim barat dan musim transisi. Periode musim timur berlangsung pada bulan Juni sampai November. Pada periode musim ini adalah saat di mana nelayan cumi-cumi dari Tanjung Luar melakukan aktivitas penangkapan di Pulau Salura, hal ini disebabkan pada musim ini kondisi sumberdaya cumi-cumi di perairan Salura mengalami kelimpahan. Namun demikian tidak semua bulan dalam periode ini adalah musim kelimpahan cumi-cumi. Musim kelimpahan cumi-cumi hanya berlangsung pada bulan September, Oktober dan November. Pada bulan Juni, Juli dan Agustus merupakan kelimpahan sedang.
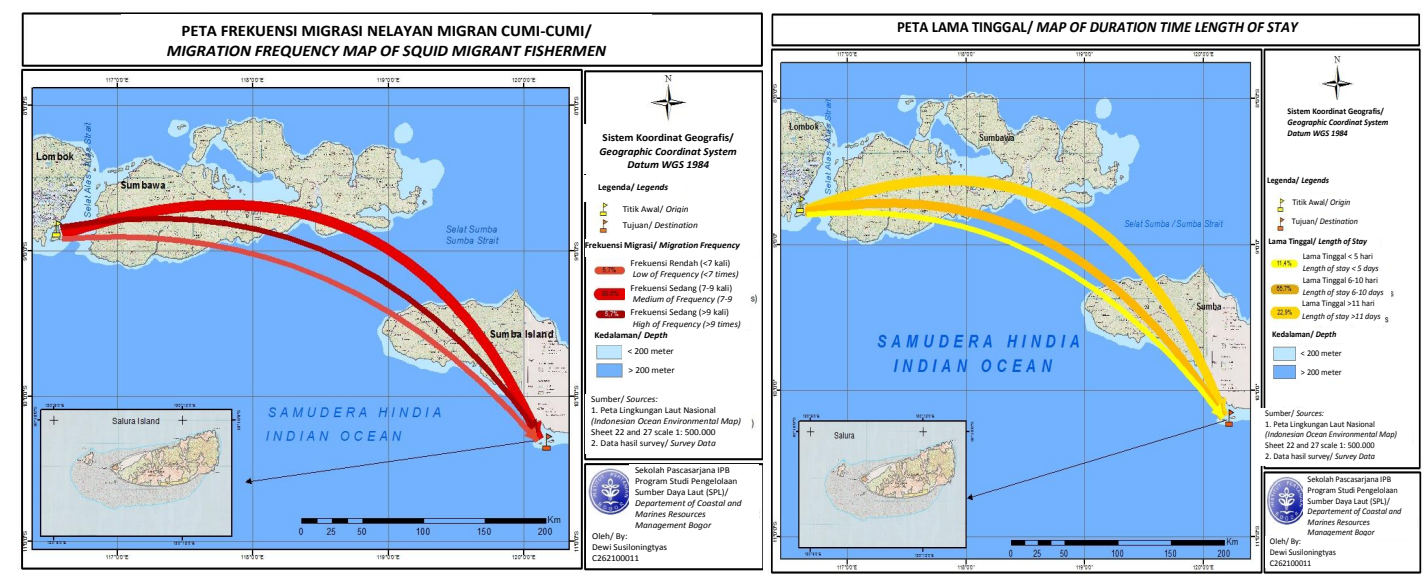

Gambar 5.Peta Frekuensi Migrasi dan Lama Tinggal di Daerah Tujuan Migrasi Figure 5. Migration Frequency Map and Length of Stay at Migration Destination

Sumber : Peta Lingkungan Laut Nasional lembar 22, 27 dan data primer hasil wawancara, 2012/ Source: Map of National Marine Environment, sheet of 22,27 and Primary Data Survey Analysis 2012 
Pola yang berbeda ditunjukkan pada saat periode musim barat, yaitu berlangsung pada bulan Januari sampai Maret. Pada periode musim ini nelayan andon tidak melakukan migrasi musiman ke Salura untuk aktivitas penangkapan cumi-cumi. Bagi nelayan andon, periode bulan ini adalah bulan dimana mereka berganti melakukan aktivitas di daerah asal mereka dengan menangkap ikan jenis lain. Nelayan tidak berani melaut hingga ke Salura, karena kondisi cuaca yang berbahaya, yaitu terhalang gelombang tinggi dan angin. Periode ini disebut sebagai periode tidak berkelimpahan cumi-cumi bagi mereka.Selain kedua periode musim ini, nelayan juga mengkategorikan musim penangkapan dengan periode musim transisi .Periode musim transisi berlangsung dari Maret sampai Mei, serta pada saat bulan Desember. Pada periode bulan ini nelayan cumi-cumi masih melakukan penangkapan cumi-cumi, yaitu pada bulan Maret dan Mei, meskipun hasil tangkapannya relatif jauh lebih sedikit. Berdasarkan penelitian partisipatif dari informasi responden, keberangkatan mereka melakukan migrasi ke Pulau Salura adalah mengikuti posisi bulan dalam setiap migrasi musiman yang dilakukan. Nelayan berangkat migrasi untuk aktivitas penangkapan cumi-cumi pada saat akhir bulan terang yaitu berkisar tanggal dua belas sampai empat belas, karena mereka harus tiba di Salura pada bulan gelap. Pola migrasi ini dapat dilihat pada Gambar 6.

\section{Hasil Pemodelan Penangkapan Cumi-Cumi}

Hasil model secara keseluruhan menunjukkan bagaimana interaksi yang terbaik antara waktu regenerasi cumi-cumi, jumlah alat tangkap atau kapal yang terlibat, serta hasil tangkapan pada kondisi populasi kelimpahan cumi-cumi terbanyak. Dari interaksi dan perilaku agen dapat ditentukan regulasi yang paling memungkinkan untuk pembatasan yang diperlakukan terhadap agen dan lingkungan. Variasi kondisi pengaturan penangkapan cumi dibedakan dari keterlibatan kapal sedikit, sedang dan banyak dalam waktu satu tahun. Adapun kondisi populasi cumi-cumi berdasarkan pada data hasil tangkapan cumi-cumi oleh nelayan, dengan asumsi untuk waktu regenerasi cumi-cumi adalah empat puluh dua hari, sesuai dengan siklus hidup cumi-cumi.

Gambar 7 memperlihatkan hasil analisis untuk pemodelan penangkapan dengan kategori keterlibatan kapal dengan jumlah relatif sedikit, yaitu 1 sampai 15 unit per tahun. Kondisi terbaik adalah ketika jumlah kelimpahan populasi cumi-cumi berada pada kondisi berlimpah terbanyak, meskipun hasil panen cumi-cumi yang dapat diambil belum tentu jumlahnya lebih banyak. Kondisi pada saat keterlibatan kapal berjumlah 14 unit merupakan kondisi terbaik, yaitu dengan pemanenan sebesar 887 kuintal akan menciptakan kelimpahan cumi-cumi sebanyak 331 kuintal (kondisi 1).

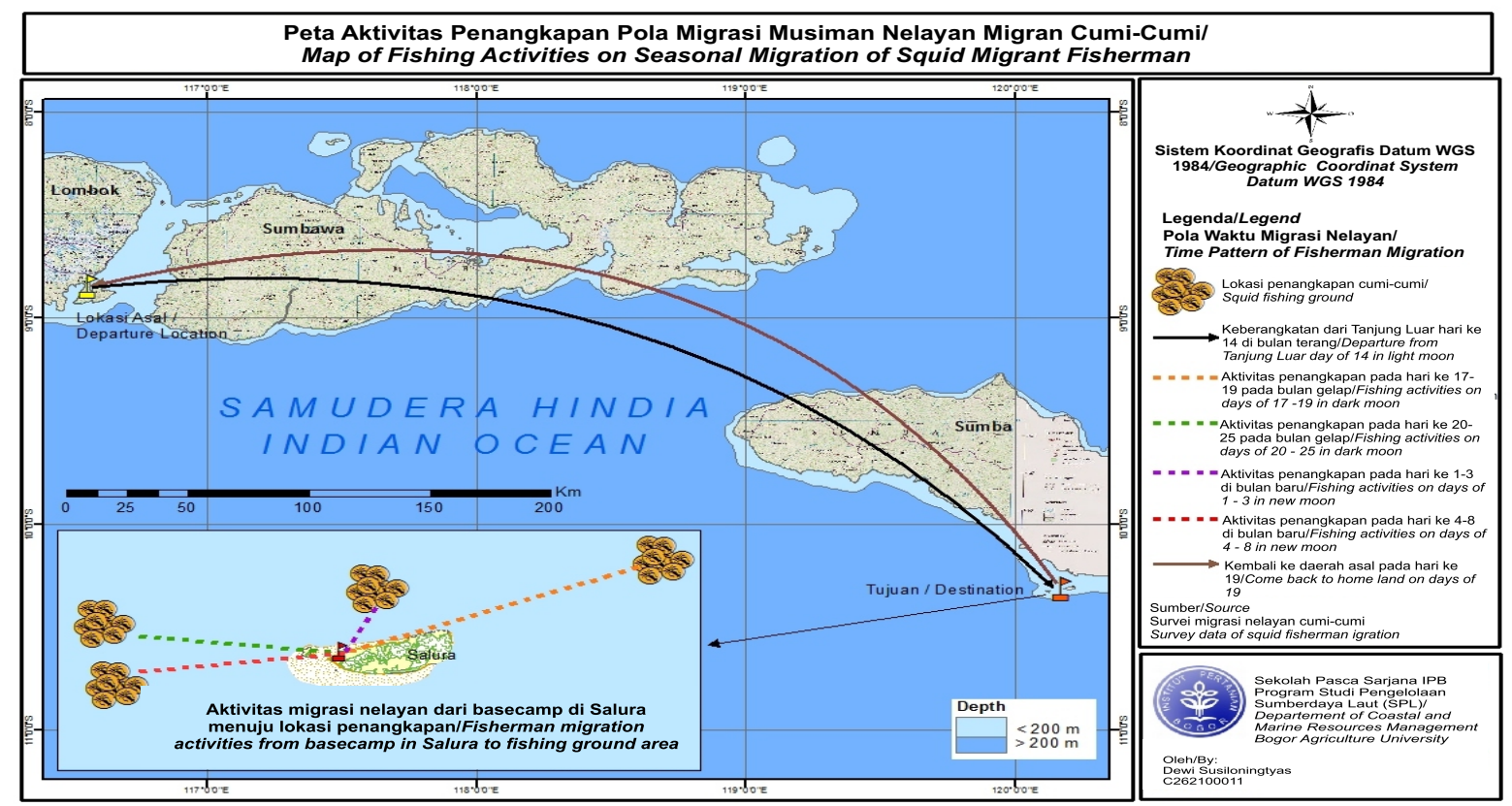

Gambar 6. Peta Aktivitas Penangkapan Menuju Lokasi Fishing ground Figure 6. Map of Fishing Activites to Fishing Ground

Sumber : Data Primer Olahan (2012)/Source : Primary Data Survey Analysis (2012) 


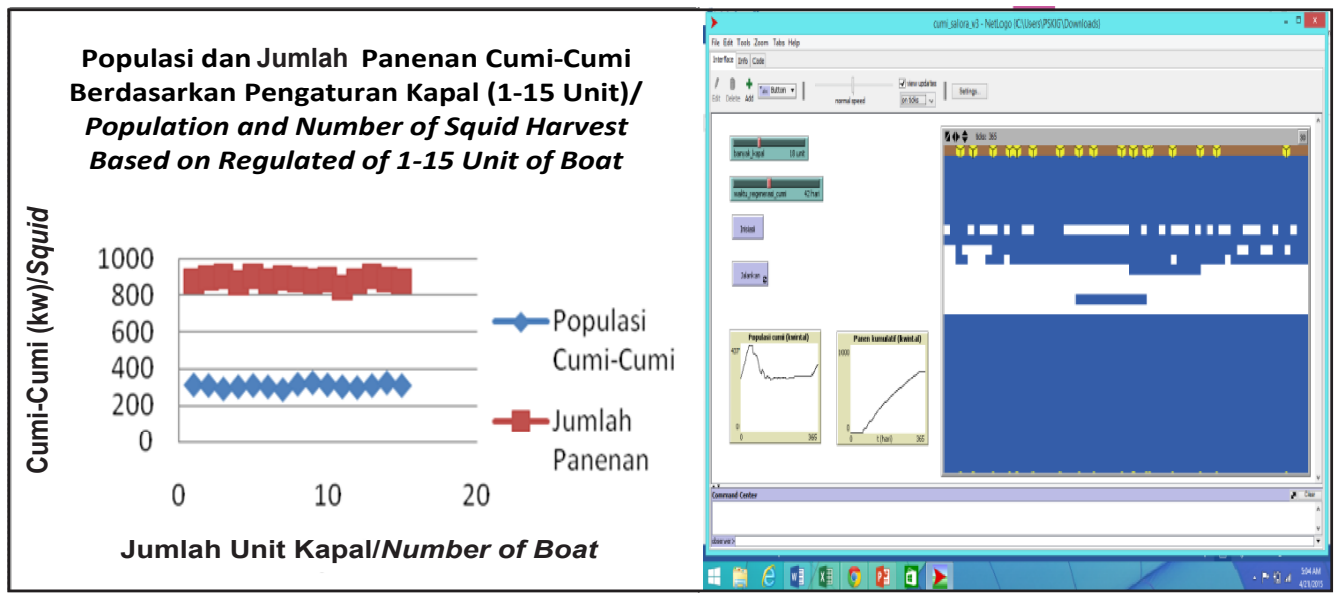

Gambar 7. Netlogo Model untuk Pengaturan Penangkapan Kondisi 1 Figure 7. The First Condition of Fishing Regulation with Netlogo Model Sumber : Analisis Data Pemodelan, 2015/Source: Modelling Data Analysis, 2015

Grafik dariinteraksi dan perilaku agen dalam pemodelan untuk karakteristik kategori kapal dengan jumlah sedang dapat dilihat pada Gambar 8. Hasil analisis berikutnya adalah untuk kategori kapal penangkapan denganjumlah sedang, yaitu 16 sampai 30 unit. Keterlibatan jumlah kapal sebanyak 18 unit tiap tahunnya merupakan kondisi terbaik (kondisi 2), yaitu menciptakan kelimpahan populasi cumi sebesar 330 kuintal, dengan pemanenan sebanyak 913 kuintal.

Pengaturan untuk keterlibatan alat tangkap yang digambarkan dengan jumlah unit kapal yang beroperasi, maka kondisi 3 ini relatif menghasilkan kelimpahan cumi-cumi yang lebih besar daripada kondisi 1. Hasil analisis ini dapat dilihat pada Gambar 7.
Analisis terhadap pengaturan untuk jumlah kapal dengan unit banyak, yaitu jumlah kapal 30-50, juga menemukan satu kondisi terbaik. Kondisi ini ditentukan dari data kelimpahan populasi cumi dan jumlah panenan yang dapat dilakukan. Pemilihan kondisi yang terbaik adalah pada saat angka populasi cumi-cumi menunjukkan jumlah populasi yang tertinggi. Hal ini sesuai dengan tujuan pengelolaan untuk keberlanjutan sumberdaya cumi-cumi yang menjadi ketergantungan hidup para agen yang ada. Berdasarkan konsep keberlanjutan sumberdaya, maka hasil pemodelan menunjukkan bahwa dengan keterlibatan kapal sejumlah 32 unit kapal, maka kelimpahan populasi cumi mencapai 327 kuintal dengan hasil panen sebesar 870 kuintal. Ini adalah kondisi terbaik 3 yang dapat menjadi alternatif pilihan untuk model yang terbaik.

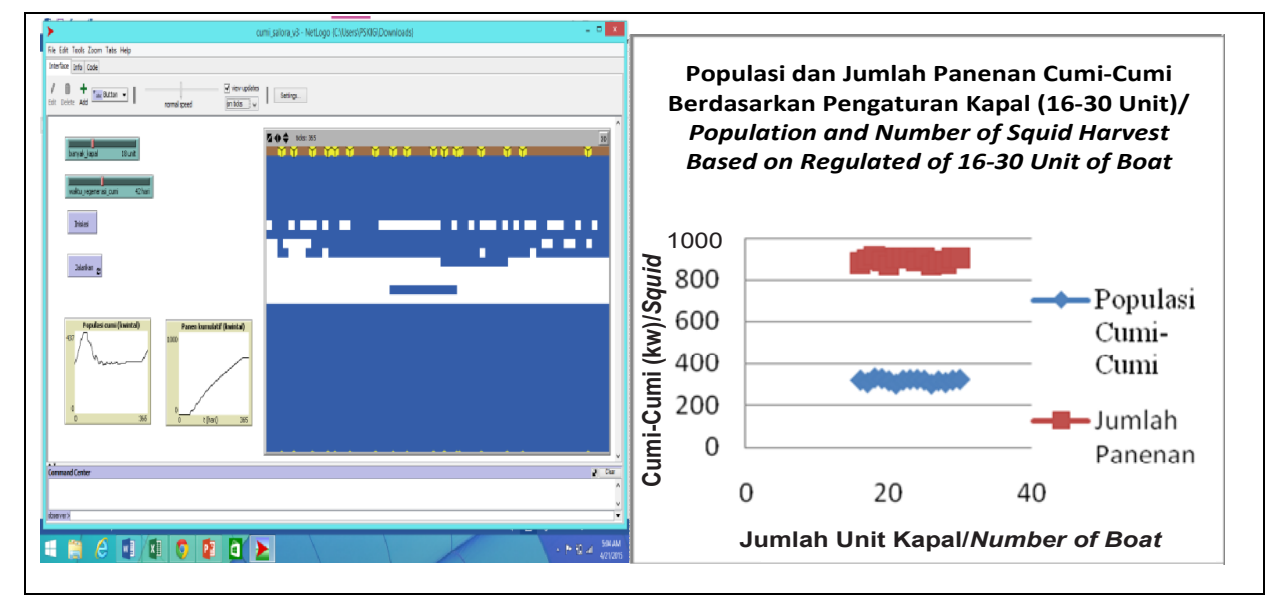

Gambar 8. Netlogo Model untuk Pengaturan Penangkapan Kondisi 2 Figure 8. The Second Condition of Fishing Regulation With Netlogo Model Sumber : Analisis Data Pemodelan, 2015/Source: Modelling Data Analysis, 2015 


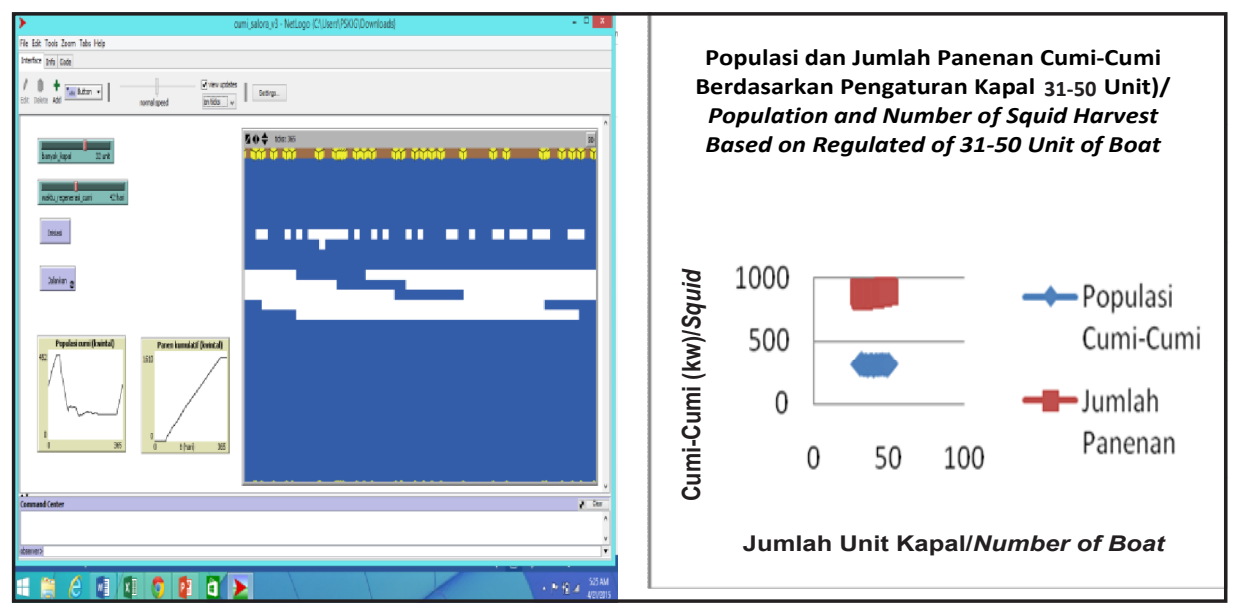

Gambar 9. Netlogo Model untuk Pengaturan Penangkapan Kondisi 3

Figure 9. The Third Condition of Fishing Regulation With Netlogo Model

Sumber : Analisis Data Pemodelan, 2015/Source : Modelling Data Analysis, 2015

Dalam pemodelan ini dihasilkan tiga alternatif kondisi yang terbaik dari masing-masing kategori karakteristik kapal. Dari alternatif model yang terbentuk akan dihasilkan regulasi yang paling tepat dari pilihan alternatif ini (K1, K2, serta K3). Pengaturan sebagai kesimpulan pengelolaan terbaik dari model penangkapan yang ada adalah dengan memilih variasi kelimpahan populasi cumi-cumi terbanyak, serta mampu menghasilkan pendapatan tertinggi, yaitu dari jumlah panenan yang bisa dilakukan.

Hasil analisis menunjukkan bahwa pengaturan terbaik adalah pada kondisi 2 (K2). Kondisi 2 ini merupakan pilihan terbaik yaitu membatasi keterlibatan kapal dalam aktivitas penangkapan oleh nelayan andon cumi di Pulau Salura dengan jumlah 18 unit kapal tiap tahun, sehingga akan menciptakan kelimpahan cumi-cumi sebesar 330 kuintal dengan jumlah panenan sebesar 913 kuintal. Dari komposisi populasi cumi-cumi dan hasil panen cumi tampak bahwa keberlanjutan cumi-cumi dengan regenerasi cumi 42 hari akan dapat menjamin keberlanjutan cumi-cumi, serta di sisi lain dapat menciptakan pendapatan atau keuntungan yang tinggi juga. Adapun asumsi regenerasi cumi-cumi dalam waktu 42 hari ini adalah hasil penelitian dari Omar (2002) tentang siklus hidup cumi-cumi. Dalam satu tahun dengan pola frekuensi migrasi sebanyak 9 kali kedatangan, maka maksimal alat tangkap yang boleh dibawa untuk satu orang nelayan andon adalah 18 unit alat tangkap atau kapal dalam waktu satu tahun, sehingga rata rata dalam satu kali migrasi selama kurang lebih 15 hari lama tinggal, satu nelayan andon hanya dapat membawa 2 alat tangkap.

\section{KESIMPULAN DAN IMPLIKASI KEBIJAKAN}

Pemodelan berbasis agen sangat tepat diterapkan dalam pemodelan aktivitas penangkapan sistem perikanan cumi-cumi di Pulau Salura. Hal ini dikarenakan perilaku agen dan aktivitias setiap agen dapat dianalisis secara rinci. Pengambilan keputusan untuk melakukan migrasi musiman yang dilakukan oleh nelayan andon dapat dimodelkan dengan identifikasi karakteristik jumlah kapal atau alat tangkap yang dibawa serta waktu regenerasi cumi-cumi. Strategi yang dibuat untuk menciptakan keberlanjutan populasi cumi-cumi dengan jumlah yang selaras dengan waktu regenerasi cumi-cumi sudah dapat diidentifikasi dengan pemodelan berbasis agen ini. Populasi cumi-cumi sebesar 330 kuintal per tahun dengan waktu regenerasi cumi-cumi tiap 42 hari adalah kondisi yang tepat. Melalui pengaturan keterlibatan kapal sejumlah 18 unit tiap tahun, maka mampu menghasilkan panenan, yaitu sebesar 913 kuintal tiap tahun.

Dari simulasi model penangkapan dan pola migrasi yang ada, maka kebijakan untuk pengelolaan sistem perikanan cumi-cumi di Pulau Salura, terkait dengan aktivitas kedatangan nelayan andon ini harus dapat diterapkan secara tegas. Bentuk nyata dari implikasi model penangkapan itu adalah melakukan pembatasan jumlah alat tangkap yang dibawa ke Pulau Salura. Adapun maksimal alat tangkap yang boleh dibawa untuk satu orang 
nelayan andon adalah 18 unit alat tangkap atau kapal dalam waktu satu tahun, sehingga rata rata dalam satu kali migrasi selama kurang lebih 15 hari lama tinggal, satu nelayan andon hanya dapat membawa 2 alat tangkap.

Peningkatan keterlibatan penduduk lokal dalam aktivitas penangkapan cumi-cumi di Pulau Salura ini perlu dirumuskan secara tepat. Kebijakan yang dibuat tidak hanya antar pelaku lokal, tetapi perlu keterlibatan akademisi, swasta (Businessman), pemerintah (Government) dan Community untuk mengelola sistem perikanan cumi ini. Keterlibatan akademisi dapat dilakukan dengan aktivitas penelitian terkait, seperti topik migrasi cumi-cumi secara in situ dan proyeksi potensi penduduk lokal untuk dapat mempunyai ketrampilan menjadi nelayan cumi. Sektor swasta dan pemerintah perlu bersinergi, terutama sebagai pendukung dalam pemasaran, regulasi harga dan pengurusan administrasi perijinan untuk kegiatan nelayan andon. Keduanya perlu koordinasi dan transparansi dalam kegiatan ini. Adapun untuk penduduk lokal, pemerintah dapat memberikan kontribusi peningkatan ketrampilan dan subsidi alat tangkap. Adapun keterlibatan komunitas yang punya perhatian terhadap pulau-pulau kecil seperti Salura dapat lebih berperan aktif untuk memantau kegiatan ini agar konservasi ekosistem pesisir dan lautan Pulau Salura dapat tetap terjaga. Kegiatan yang dapat dilakukan adalah dengan memberikan penyuluhan dan pendampingan untuk penduduk lokal Salura dan nelayan andon untuk upaya konservasi dan pengelolaan secara tepat dan bijaksana.

\section{DAFTAR PUSTAKA}

Omar, S. B. A. 2002. Biologi Reproduksi Cumi-Cumi (Sepioteuthis Lessoniana Lesson). Phuket Marine Biological Center (25) :139-145.

Overa, R. 2001. Institutions, Mobility and Resilience in the Fante Migratory Fisheries of West Africa, Working Paper 2001: 2, Chr. meichelsen Institute, Bergen Norway.

Cassel, S., S. R. Curran and R. Kramer. 2005. Do Migrants degrade coastal environment? Migration, Natural Resources Extraction and Poverty in North Sulawesi, Indonesia. Human Ecology 33 (3): 329-363.

Nunan, F. 2006. Empowerment and Institutions Managing Fisheries in Uganda. World Development 34 (7): 1316-1332.

Gao, L. and H. Atakelty. 2011. An Agent Based Integrated Model of Recreational Fishing and Coral Reef Ecosystem Dynamics for Site Closure strategy Analysis. Proceding of 19th International Congres on Modelling and Simulation, Perth Australia. December: 3105-3111.

Health, B. L. \& R. R. Hill. 2010. Some insights into the emergence of agent based modelling. Journal of Simulation 4:163-169.

Macal, C. M. and M. J. North. 2010. Tutorial and Agent Based Modelling and Simulation. Journal of Simulation 4:151-162.

Schluter, M., L. Heather and L. Simon. 2009. Managing Water Use trade offs in a semi arid river Delta to Sustain Multiple Ecosystem Services: A Modelling Approach.The ecological Society of Japan, Januari:1-11.

Yu Run, P. Minling, F. R. Steven and L. Ping Sun. 2009. A Prototype Agent Based Fishery Management Model of Hawaii's Longline Fishery. Proceding of 18th World Imacs Congres, Cairns, Australia. Juni: 2170-2177. 
Lampiran 1. Informasi Pemodelan Penangkapan Cumi-Cumi di Pulau Salura. Appendix 1. Information of Squid Fishing Modelling at Salura Island.

\begin{tabular}{|c|c|c|}
\hline $\begin{array}{l}\text { Penjelasan Model/ } \\
\text { Description of Model }\end{array}$ & $\begin{array}{c}\text { Cara Kerja Model/ } \\
\text { The Working of Model }\end{array}$ & $\begin{array}{c}\text { Cara Menjalankan Model/ } \\
\text { How to run a model }\end{array}$ \\
\hline $\begin{array}{l}\text { Model penangkapan atau } \\
\text { Pemanenan cumi-cumi di } \\
\text { Pulau Salura selama } 1 \text { tahun/ } \\
\text { Fishing activity and squid } \\
\text { model at Salura in one year } \\
\text { Warna biru berkorespondensi } \\
\text { dengan perairan Salura/ Blue } \\
\text { colour identified with Salura } \\
\text { ocean } \\
\text { Warna putih dikonversi } \\
\text { dengan } 1 \text { kuintal cumi- } \\
\text { cumi/ White colour same } \\
\text { conversion with one quintal of } \\
\text { squid } \\
\text { Pita warna coklat } \\
\text { berkorespondensi dengan } \\
\text { Pulau Salura/ Brown colour } \\
\text { corespondence with Salura } \\
\text { Island }\end{array}$ & $\begin{array}{l}\text { - } \quad \text { Tiap kapal memanen } \\
\text { cumi-cumi Tanpa melewati } \\
\text { kapasitas penyimpanan } \\
\text { cumi-cumi di kapal } \\
\text { tersebut/ Each of boat } \\
\text { harvesting squid without } \\
\text { passing of storring } \\
\text { capacity of squid } \\
\text { - Cumi-cumi berkembang } \\
\text { biak dengan waktu } \\
\text { regenerasi } 42 \text { hari/ Squid } \\
\text { reproduced within } 42 \text { days } \\
\text { Kapal tidak berangkat } \\
\text { ke P Salura pada bulan } \\
\text { Januari,Februari dan } \\
\text { Desember / The ship } \\
\text { did not go to Salura in } \\
\text { January, February and } \\
\text { December }\end{array}$ & $\begin{array}{l}\text { - Tentukan banyak kapal } \\
\text { yang terlibat dalam } 1 \text { tahun/ } \\
\text { Specify many boat were } \\
\text { involved in the fishing activity } \\
\text { in one year } \\
\text { _ Tentukan banyak cumi-cumi } \\
\text { yang ada/ Specify number of } \\
\text { squid } \\
\text { - Tentukan tombol "inisiasi"/ } \\
\text { Specify"inisiasi" button } \\
\text { - Tentukan tombol : "jalankan"/ } \\
\text { Specify "jalankan" button }\end{array}$ \\
\hline
\end{tabular}

Sumber: Analisis ABM dengan Netlogo 6.2, 2015/Source : ABM Analysis with Netlogo 6.2, 2015 